\title{
Assessment of Psychological Distress among Pregnant Women in Kirkuk City
}

\author{
Abbas Lateef Muhe AL-deen*
}

\begin{abstract}
Background and Objective: Stress is a psychological state of fatigue or physical fatigue affects an individual in response to psychological pressure or unexpected real life. Stress can be short-term or longterm, Feeling stressed is common during pregnancy, but too much stress can make a pregnant woman uncomfortable. Stress can make trouble sleeping, headaches, loss of appetite or overeating. Some studies show that high levels of stress in pregnancy may cause certain problems during childhood. The purpose of this study was to assess the psychological distress among pregnant women's in Kirkuk city, as well as to find a relationship between psychological distress and some socio- demographic characteristics such as (No. of children, socioeconomic status, pregnancy stage, woman's age).

Material and Method: A descriptive study was carried out in gynecological consultation at hospitals (Azadi teaching, general Kirkuk) in Kirkuk city, to assess the psychological distress in pregnant women for a period from the $15^{\text {th }}$ of June 2013 and up to the $25^{\text {th }}$ of November, 2013 to achieve the objectives of the study. A probability (purposive) sample of (120) pregnant women's. Developed questionnaire was constructed for the purpose of the study, which consisted of three parts: the demographic characteristics; medical data and assessment psychological distress among pregnant women. The data were collected through the use of the interview. They were analyzed through the application of descriptive statistical analysis (frequency, percentage) and inferential statistical (chi-square) .

Results: The findings of the study indicated that (35\%) were in the age group (22-26), and (85\%) were from the urban, $(30.84 \%)$ of the sample were graduate from Institute and above, (70\%) of them housewife , $(65.83 \%)$ of the sample had barely sufficient monthly income. Regarding to the medical data finding of the study indicated that $(57.5 \%)$ of them in the $3^{\text {rd }}$ trimester, the Miscarriage in the whole study represented $(75.83 \%)$ is null, $(29.17)$ have null children, $(55.83 \%)$ overweight, $(94.17 \%)$ no smoking, $(88.33 \%)$ have no history of chronic disease ,(79.1\%) have no pregnancy induced hypertension ,(98.23\%) have no pregnancy induced diabetic mellitus.

Conclusions: The psychological distress in the study sample was founded in the third Trimester and founds a Significant relationship between Pregnancy Stage and Psychological Distress. Also founds a Significant relationship between socioeconomic status and Psychological Distress. As the study concluded that most of the pregnant women were to have moderate psychological distress.
\end{abstract}

Keywords : Assessment, Psychological Distress, Pregnant Women, Pregnancy, Trimesters , Miscarriage.

\section{INTRODUCTION}

Pregnancy is a major life event that confronts women with specific physical, psychological and social changes (Van Bussel et al., 2006). Common causes of psychological problems in the peripartum are Previous history of pregnancy loss, History of perinatal depression, Unplanned pregnancy, Concern about the fetus, Marital difficulties ,Lack of social support, Increased life stress, Financial stress (Varkukla et al., 2009). Stress is a feeling person get when faced with a challenge, Stress can be short-term or long-term, Feeling stressed is common during pregnancy, but too much stress can make pregnant woman uncomfortable. Stress can make trouble sleeping, headaches, loss of appetite or overeat (O'Connor et al., 2003). Some studies show that high levels of stress in pregnancy may cause certain problems during childhood, like having trouble paying attention or being afraid (Schneider et al., 2002). High levels of stress that continue for a long time may cause health problems, When a pregnancy, this type of stress can increase the chances of having a premature baby or a low-birth weight baby (Eva et al, 2006). Stress during pregnancy may effects on the immune system of the fetus and may result in predisposing newborn to allergy (Sausenthaler, 2009). There is some evidence to suggest that stress late in pregnancy (third trimester), in comparison to early prenatal stress (second

* Assistant lecturer/College of Nursing / University of Kirkuk 
trimester), is more predictive of preterm delivery (Rini et al., 2000). Prevalence rates of psychosocial stress during pregnancy are substantial. Evidence for associations between psychosocial stress and birth outcomes is inconsistent, It's possible that stress may also affect the baby's brain development or immune system. The prenatal stress is associated with preterm delivery and shorter gestation (DunkelSchetter et al., 2000; Homffman et al., 2000). The risk factors, nature and timing of women's psychological disturbance during the pregnancy and the postpartum period, are suggested to differ according to these maternal orientations (Raphael-Leffm, 2005). Psychosocial factors have been the subject of inquiries into the etiology of preterm birth. Prior research has focused on associations between psychosocial factors such as maternal exposure to stress and anxiety with preterm birth (Levine et al, 2003). Alteration in our routines even grateful ones can be stressful. Psychological stress is a particular relation between the person and environment that is appraised by the person exceeding his or her resources and threatening well-being (Lin et al., 2004; Michelle et al., 2009). Many studies have suggested that stress and stress hormones have a role in the etiology of preterm birth (PTB) (RichEdwards et al, 2005). It has been hypothesized that stress increases levels of cortisol and corticotrophin-releasing hormone $(\mathrm{CRH})$, and increased CRH causes PTB (Wadhwa et al., 2001). Under stress-inducing laboratory challenges, the hypothalamic-pituitary-adrenal axis responds by releasing both cortisol and CRH. During pregnancy, cortisol stimulates the production of $\mathrm{CRH}$ in the placenta, and both cortisol and CRH have been found to be higher in medically complicated pregnancies in several studies (Majzoub et al, 2001; Sandman et al, 2006; McLean et al, 2000). The primary purpose of this study was To assess the Psychological distress among pregnant women, and To find out the relationship between Psychological distress during pregnancy and some socio-demographic data (Number of children, Socioeconomic Status, Pregnancy Stage, Woman's age).

\section{MATERIALS AND METHODS}

A descriptive study was carried out from the $15^{\text {th }}$ of June, 2013 to the $25^{\text {th }}$ November, 2013 in order to achieve the objectives of the present study. A probability (purposive) samples that consisted of (120) pregnant woman that attending to the gynecological consultation at hospitals (Azadi teaching, general Kirkuk) in Kirkuk city. The sample age ranges between (17-41) years. The study tools were developed to achieve the purpose of this study. Developed questionnaire was constructed for the purpose of the study, which consisted of three parts: the demographic characteristics; medical data; and assessment of psychological distress among pregnant women. Each woman spends approximately (10$15 \mathrm{~min})$ to respond to the interview. The demographic data sheet includes, the woman's age, residence, level of education of women's, occupation of women's, pregnancy stage, socioeconomic status, miscarriage, and a number of children's. The medical data sheet includes: Body mass index, chronic disease, pregnancy induced H.T, pregnancy induced D.M. The assessment of psychological distress tools contains 12 items, that focus on pregnant woman psychological distress for example " been able to concentrate on whatever you're doing? " and " been thinking of yourself as a worthless person?" , and it consist of three scale check (Always) if something occurs every day, (Sometimes) if it occurs 2 to 4 times a week, and (Never) if nothing there is occurs.

\section{RESULTS}

Table (1): Demonstrates Socio-demographic characteristic of the whole study samples

\begin{tabular}{|c|c|c|c|}
\hline \multicolumn{2}{|c|}{ Socio-demographic characteristic } & Frequency $(f)$ & Percentage (\%) \\
\hline \multirow{5}{*}{ Women's Age } & $17-21$ year & 17 & 14.17 \\
\hline & 22-26 year & 42 & 35 \\
\hline & 27-31 year & 35 & 29.16 \\
\hline & $32-36$ year & 18 & 15 \\
\hline & $37-41$ year & 8 & 6.67 \\
\hline \multicolumn{2}{|c|}{ Total } & 120 & 100 \\
\hline \multirow{2}{*}{ Residence } & Urban & 84 & 70 \\
\hline & Rural & 36 & 30 \\
\hline \multicolumn{2}{|c|}{ Total } & 120 & 100 \\
\hline
\end{tabular}




\begin{tabular}{|c|c|c|c|}
\hline \multirow{6}{*}{$\begin{array}{c}\text { Level of } \\
\text { Education of } \\
\text { Women's }\end{array}$} & Not read \& not write & 12 & 10 \\
\hline & Read \& write & 10 & 8.33 \\
\hline & Primary School & 32 & 26.67 \\
\hline & Intermediate School & 16 & 13.33 \\
\hline & Secondary School & 13 & 10.83 \\
\hline & Institutes or above & 37 & 30.84 \\
\hline \multicolumn{2}{|r|}{ Total } & 120 & 100 \\
\hline \multirow{3}{*}{$\begin{array}{l}\text { Occupation of } \\
\text { Women's }\end{array}$} & Employer & 24 & 20 \\
\hline & Housewife & 84 & 70 \\
\hline & Student & 12 & 10 \\
\hline \multicolumn{2}{|c|}{ Total } & 120 & 100 \\
\hline \multirow{3}{*}{$\begin{array}{l}\text { Pregnancy } \\
\text { Stage }\end{array}$} & $1^{\text {st }}$ Trimester & 20 & 16.67 \\
\hline & $2^{\text {nd }}$ Trimester & 31 & 25.83 \\
\hline & $3^{\text {rd }}$ Trimester & 69 & 57.5 \\
\hline \multicolumn{2}{|c|}{ Total } & 120 & 100 \\
\hline \multirow{3}{*}{$\begin{array}{c}\text { Socioeconomic } \\
\text { Status }\end{array}$} & Insufficient & 11 & 9.17 \\
\hline & Barely sufficient & 79 & 65.83 \\
\hline & Sufficient & 30 & 25 \\
\hline \multicolumn{2}{|c|}{ Total } & 120 & 100 \\
\hline \multirow{3}{*}{$\begin{array}{c}\text { No. of } \\
\text { Children's }\end{array}$} & Null & 35 & 29.17 \\
\hline & $\frac{1-2}{1-2}$ & 59 & 49.17 \\
\hline & 3 and more & 26 & 21.66 \\
\hline \multicolumn{2}{|c|}{ Total } & 120 & 100 \\
\hline \multirow{3}{*}{ Miscarriage } & Null & 91 & 75.83 \\
\hline & $1-2$ & 24 & 20 \\
\hline & 3 and more & 5 & 4.17 \\
\hline & 120 & 120 & 100 \\
\hline
\end{tabular}

Table (2): Assessment of psychological distress among pregnant women with percentage, mean of score \& significancy

\begin{tabular}{|c|c|c|c|c|c|c|c|c|c|}
\hline \multirow{2}{*}{ NO. } & \multirow{2}{*}{ Items } & \multicolumn{2}{|c|}{ Never } & \multicolumn{2}{|c|}{ Sometime } & \multicolumn{2}{|c|}{ Always } & \multirow{2}{*}{ M.S } & \multirow{2}{*}{$\mathbf{S}$} \\
\hline & & $\mathbf{F}$ & $\%$ & $\mathbf{F}$ & $\%$ & $\mathbf{F}$ & $\%$ & & \\
\hline 1. & $\begin{array}{l}\text { been able to concentrate on } \\
\text { whatever you're doing? }\end{array}$ & 11 & 9.17 & 87 & 72.5 & 22 & 18.33 & 2.09 & $\mathbf{M}$ \\
\hline 2. & lost much sleep over worry? & 19 & 15.83 & 31 & 25.83 & 70 & 58.34 & 2.42 & $\mathbf{H}$ \\
\hline 3. & $\begin{array}{l}\text { felt capable of making decisions } \\
\text { about things? }\end{array}$ & 10 & 8.33 & 89 & 74.17 & 21 & 17.5 & 2.09 & $\mathbf{M}$ \\
\hline 4. & felt constantly under strain? & 35 & 29.16 & 71 & 59.17 & 14 & 11.67 & 1.82 & $\mathbf{M}$ \\
\hline 5. & $\begin{array}{l}\text { felt you couldn't overcome your } \\
\text { difficulties? }\end{array}$ & 23 & 19.16 & 89 & 74.17 & 8 & 6.67 & 1.87 & $\mathbf{M}$ \\
\hline 6. & $\begin{array}{l}\text { been able to enjoy your normal day- } \\
\text { to-day Activities? }\end{array}$ & 16 & 13.33 & 88 & 73.34 & 16 & 13.33 & 2 & $\mathbf{M}$ \\
\hline 7. & been taking things hard? & 50 & 41.67 & 58 & 48.33 & 12 & 10 & 1.68 & $\mathbf{L}$ \\
\hline 8. & $\begin{array}{l}\text { been able to face up to your } \\
\text { problems? }\end{array}$ & 14 & 11.67 & 87 & 72.5 & 19 & 15.83 & 2.04 & $\mathbf{M}$ \\
\hline 9. & $\begin{array}{l}\text { been feeling unhappy and } \\
\text { depressed? }\end{array}$ & 27 & 22.5 & 80 & 66.67 & 13 & 10.83 & 1.88 & $\mathbf{M}$ \\
\hline 10. & been losing confidence in yourself? & 64 & 53.33 & 49 & 40.84 & 7 & 5.83 & 1.52 & $\mathbf{L}$ \\
\hline 11. & $\begin{array}{l}\text { been feeling reasonably happy, all } \\
\text { things considered? }\end{array}$ & 17 & 14.17 & 75 & 62.5 & 28 & 23.33 & 2.09 & $\mathbf{M}$ \\
\hline 12. & $\begin{array}{l}\text { been thinking of yourself as a } \\
\text { worthless person? }\end{array}$ & 79 & 65.83 & 39 & 32.5 & 2 & 1.67 & 1.35 & $\mathbf{L}$ \\
\hline
\end{tabular}


Table (3): Relationship between No. of children and psychological distress

\begin{tabular}{|c|c|c|c|c|c|c|c|c|c|}
\hline \multirow{2}{*}{ No. Of Children } & \multicolumn{2}{|c|}{ Alwavs } & \multicolumn{2}{|c|}{ Sometimes } & \multicolumn{2}{|c|}{ Never } & \multicolumn{2}{|c|}{ Total } & P. Value \\
\hline & $\mathbf{F}$ & $\%$ & $\mathbf{F}$ & $\%$ & $\mathbf{F}$ & $\%$ & $\mathbf{F}$ & $\%$ & \multirow{8}{*}{$>0.05$} \\
\hline Null & 51 & 20.31 & 241 & 27.44 & 116 & 37.30 & 408 & 28.33 & \\
\hline 1 & 112 & 44.62 & 215 & 24.49 & 45 & 14.47 & 372 & 25.83 & \\
\hline 2 & 45 & 17.92 & 219 & 24.94 & 84 & 27.01 & 348 & 24.17 & \\
\hline 3 & 11 & 4.38 & 72 & 8.20 & 25 & 8.04 & 108 & 7.5 & \\
\hline 4 & 17 & 6.80 & 63 & 7.18 & 16 & 5.14 & 96 & 6.67 & \\
\hline 5 & 15 & 5.97 & 68 & 7.75 & 25 & 8.04 & 108 & 7.5 & \\
\hline Total & 251 & 100 & 878 & 100 & 311 & 100 & 1440 & 100 & \\
\hline \multicolumn{4}{|c|}{ Value $=76.858$} & \multicolumn{3}{|c|}{$D . F=10$} & \multicolumn{2}{|c|}{ Crit. $=18.307$} & \\
\hline
\end{tabular}

Table (4): Relationship between Socioeconomic status and psychological distress

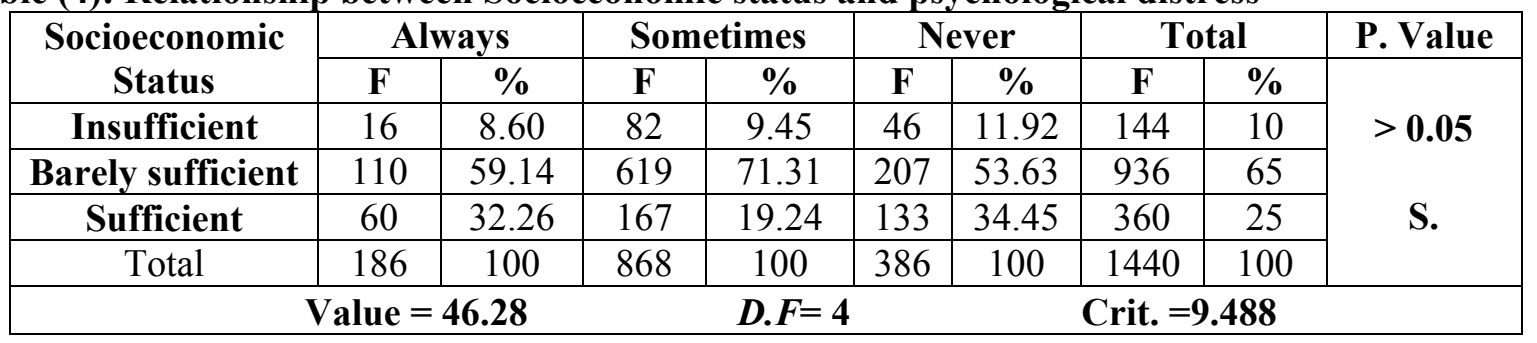

Table (5): Relationship between Pregnancy Stage and psychological distress

\begin{tabular}{|c|c|c|c|c|c|c|c|c|c|}
\hline \multirow{2}{*}{$\begin{array}{l}\text { Pregnancy } \\
\text { Stage }\end{array}$} & \multicolumn{2}{|c|}{ Always } & \multicolumn{2}{|c|}{ Sometimes } & \multicolumn{2}{|c|}{ Never } & \multicolumn{2}{|c|}{ Total } & \multirow[b]{2}{*}{ P. Value } \\
\hline & $\mathbf{F}$ & $\%$ & $\mathbf{F}$ & $\%$ & $\mathbf{F}$ & $\%$ & $\mathbf{F}$ & $\%$ & \\
\hline $1^{\text {st }}$ Trimester & 31 & 16.67 & 130 & 14.77 & 79 & 21.13 & 240 & 16.67 & \multirow{2}{*}{$>0.05$} \\
\hline $2^{\text {nd }}$ Trimester & 28 & 15.05 & 250 & 28.41 & 94 & 25.13 & 372 & 25.83 & \\
\hline $3^{\text {rd }}$ Trimester & 127 & 68.28 & 500 & 56.82 & 201 & 53.74 & 828 & 57.5 & \\
\hline Total & 186 & 100 & 880 & 100 & 374 & 100 & 1440 & 100 & \\
\hline \multicolumn{3}{|c|}{ alue } & \multicolumn{4}{|c|}{ D. $F=4$} & \multicolumn{2}{|c|}{ Crit. $=9.488$} & \\
\hline
\end{tabular}

Table (6): Relationship between Woman's age and psychological distress:

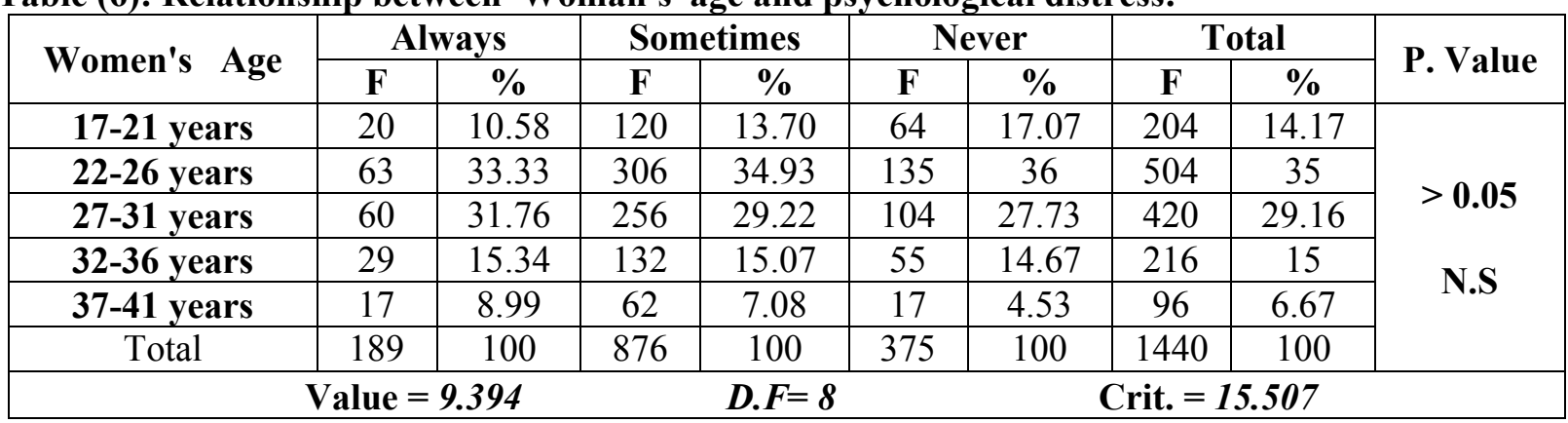

\section{DISCUSSION}

Pregnancy is known to be a major public health concern and pregnant women confront many life challenges and they have an increased risk for becoming involved stress. The consequences of stress during pregnancy on the mother and fetus, and the long-term effects on child health status, have been shown in several studies. The pregnancy stress causes changes in perinatal immune modulation and may finally bring on allergic diseases in children (Wright et al, 2005; Abigail et al, 2006; Montoro et al,
2009). High maternal stress in the first six months after delivery is associated with a greater allergen specific proliferative response (Wright et al, 2005).

In this study showed that antenatal stress is common in pregnant women in our area and a significant relationship exist between psychological distress and pregnancy stage. There was also a significant relationship between socioeconomic status and psychological distress. In this study also find a significant relationship between the number of children and 
psychological distress, and there is no significant relationship between the number of children and the psychological distress. As the study concluded that most of the pregnant women were to have moderate psychological distress. Correlation studies suggest that pregnant mothers who have chronic psychological stress are more likely to abuse or neglect their children after they are born (Stratakis and Chrouso, 1995; Naja et al., 2008). According to this thread and the results of the findings, which showed that during pregnancy moderate to high stress level is considerable therefore, the intervention of our health system is necessary to reduce stress in pregnancy. Countries with the lowest stress levels report fewer problems over economics, health, employment, and violence than countries with higher stress levels. In most developing countries, medical services, employment, economic state are low and lack of medical care can significantly increase national stress rates which those most affected by this stressor are women and children. Stressful events undergo during pregnancy may be conveyed to babies as an increased risk for allergic disease (Salynn , 2010). In a study, (9.5\%) of the woman engaged with generalized anxiety disorder (GAD) at some point in pregnancy (Buist et al. 2011). However, in this study showed nearly half pregnant women had moderate to severe stress during pregnancy. These findings show that pregnancy in our area is more stressful, and it may be due to differences between various economic, familial, social, and environmental factors. Thus we emphasize to an establishment intervention program to decrease the stress during pregnancy and this may be make allergic disease percentages decreased too. Furthermore, culture and lower levels of education play a role in the production of stress. For example, women in Pakistan have particularly stressful life because of their lack of control over their lives (Husain and Chaudhry, 2007; Mumford et al., 1999). Iran is in proximity of Pakistan and Turkey, and similarities are between both countries and stress patterns would be expected similarly. In a Turkish study, obese women had a higher score compared to normal weight women on family issues within the stress factor scale (Sanlier and Unusan, 2007). Obese pregnant women attending an intervention program seem to have the same risk of experiencing anxiety and/or depressive symptoms as do obese and postnatal women in general(Claesson et al, 2010). $40 \%$ of Iranian adults (that nearly $48 \%$ of them belong to the women group) are low physical activity. Physical inactivity, particularly in females, is common in Iran (Esteghamati et al, 2011). In this study, this item not be assessed but exercise is an ideal method to help cope with environmental stressors. It will also give feeling more energetic and ready for an opponent with day's conflict. Exercise can help ease labor and decrease some of the stress associated with the unwilling labor or delivery. In a study in Turkey, working women had higher levels of stress than nonworking women. Working women in sub scales of immune system and susceptibility to stress scale had a higher average score than nonworking women (Nevin and Fatma, 2007). Women in developing countries may experience the greater stresses than women in modern societies, and they are more likely to admit due to mental health problems. It's very important for pregnant women who have close and continuous interactions with their close friends and family members, because their conflicts, challenges , anxiety and stress will be decreased. Advise the pregnant women should be trained for stress and anger management. The people must be educated about effects of stress on the pregnancy outcome in order to reduce the incidence of asthma and allergic diseases. In studies, being in the top 15\% for antenatal anxiety at 32 weeks of gestation, approximately doubled the risk for having a son with ADHD symptoms at age 4 and 7 (Schneider et al. 1999).

\section{CONCLUSIONS}

The study concluded that the most of the pregnant women were to have moderate psychological distress, and also founds a significant relationship between pregnancy stage, socioeconomic status and the psychological distress. In addition, there are no significant relationship between the woman's age and the psychological distress.

\section{RECOMMENDATIONS}

The present study recommends that routine screening antenatally, for psychosocial vulnerability, current feelings and state of stress, with use of reliable and valid measures. The study highlighted the necessity of educational interventions and consistent prenatal care for pregnant woman to reduce their worries and concerns about pregnancy. In addition, educational programs should be designed to increase Pregnant woman knowledge about etiology, signs and symptom and treatment of stress and Providing scientific booklet, publication and journal about stress. Also recommend that further studies examining the associations of stress with pregnancy outcome 
such as premature labor and low birth weight and the psychological well-being of women such as anxiety and depression.

\section{REFERENCES}

Abigail L. Fowden, Dino A. Giussani and Alison J. Forhead . (2006). Intrauterine Programming of Physiological Systems: Causes and Consequences. Physiology. 21(1). P.p. 29-37.

Buist A, Gotman N, Yonkers KA. (2011). Generalized anxiety disorder: Course and risk factors in pregnancy. $J$ Affect Disord. Jan 24.

Claesson IM, Josefsson A, Sydsj G. (2010). Prevalence of anxiety and depressive symptoms among obese pregnant and postpartum women: an intervention study. BMC Public Health. Dec 16.10. P.p.766.

Dunkel-Schetter, C., Wadhwa, P. and Stanton, A.L. (2000). Stress and reproduction: introduction to the special section. Health Psychology. 19. P.p. 507-509.

Esteghamati A, Khalilzadeh O, Rashidi A, Kamgar M, Meysamie A, Abbasi M. (2011). Physical activity in Iran: results of the third national surveillance of risk factors of non-communicable diseases. $J$. Phys Act Health. 8(1). P.p. 27-35.

Eva M. Loomans, Tanja G.M. Vrijkotte, Manon van Eijsden , Karien Stronks, Reinoud J.B.J. Gemke, Bea R.H. (2006). Psychosocial stress during pregnancy is related to adverse birth outcomes, Department of Psychology. Tilburg university, Warandelaan .

Hoffman, S. and Hatch, M.C. (2000). Depressive symptomatology during pregnancy: Evidence foran association with decreased fetal growth in pregnancies of lower social class women. Health Psychology. 19. P.p. 535-543.

Husain N.,. Chaudhry I. B. (2007). Life stress and depression in a tribal area of Pakistan .The British Journal of Psychiatry. 190. P.p. 36-41.

Levine RE, Oandasan AP, Primeau LA, Berenson AB. (2003). Anxiety disorders during pregnancy and postpartum. Am J Perinatol 20. P.p. 239-48.

Lin YC, Wen HJ, Lee YL, Guo YL. (2004). School of Dentistry, Kaohsiung Medical University, Kaohsiung, Taiwan Are maternal psychosocial factors associated with cord immunoglobulin $\mathrm{E}$ in addition to family atopic history and mother immunoglobulin E? Clin Exp Allergy. 34(4). P.p. 548-54.

Majzoub JA, McGregor JA, Lockwood CJ, et al. (2000). A central theory of preterm and term labor: putative role for corticotropinreleasing hormone. Am J Obstet Gynecol 180. P.p. S232.

McLean M, Bisits A, Davies J, et al. (2000). Predicting risk of preterm delivery by second-trimester measurement of maternal plasma corticotropin-releasing hormone and a-fetoprotein concentrations. $A m \mathrm{~J}$ Obstet Gynecol. 181. P.p. 207.

Michelle J., Michelle B., Sheldon C., , Marina J. C., John S., Kathy T., and Rosalind J. Wright, MD, MPHa, Boston and Amherst, Mass. (2009). Maternal interpersonal trauma and cord blood IgE levels in an inner-city cohort: A life-course perspective. Journal of Allergy and Clinical Immunology. 124 (5). P.p. 954960.

Montoro J, J Mullol, I Jáuregui, I Dávila, M Ferrer, J Bartra, A del Cuvillo, J Sastre, A Valero. (2009). Stress and allergy. $J$. Investig Allergol Clin Immunol. 19(1). P.p. 40-47.

Mumford DB, Saeed K, Ahmad I, Latif S and Mubbashar MH. (1999). Stress and psychiatric disorder in rural Punjab. A community survey. The British Journal of Psychiatry. 170. P.p. 473-478

Naja Rod N.; Tage S. K.; Peter S.; Morten Grønbæk. (2008). Perceived Stress and Causespecific Mortality Among men and Women: Results From a Prospective Cohort Study. American Journal of Epidemiology. 168(5). P.p. 481-491.

Nevin Sanlier,Fatma Arpaci. A study into the effects of stress on woman's health. Humanity \&Social sciences journal. (2007), 2(2):104-109.

O'Connor TG, Heron J, Golding J, Glover V. (2003). Maternal antenatal anxiety and behavioural/emotional problems in children: a test of a programming hypothesis. Journal of Child Psychology and Psychiatry. 44 (7). P.p. 1025-36. Retrivied from http://dx.doi.org/10. 1111/1469-7610.00187 on 2012.

Raphael-Leff, J. (2005). Psychological Processes of Childbearing. The Anna Freud Centre, London.

Rich-Edwards JW, Grizzard TA. (2005). Psychosocial stress and neuroendocrine mechanisms in preterm delivery. $\mathrm{Am} J$ Obstet Gynecol. 192. P.p. S30. 
Rini, C.K., Dunkel-Schetter, C., Wadhwa, P.D. and Sandman, C.A. (2000). Psychological adaptation and birth outcomes: The role of personal resources, stress, and sociocultural context during pregnancy. Health Psychology. 18. P.p. 333-345.

Salynn Boyles. (2010). Pregnancy Stress Ups Kids' Asthma Risk. Health and pregnancy. Web medical.

Sandman CA, Glynn L, Schetter CD, et al. (2006). Elevated maternal cortisol early in pregnancy predicts third trimester levels of placental corticotropin releasing hormone (CRH): priming the placental clock. Peptides 27. P.p.1457-1463.

Sanlier N., Unusan N. (2007). The Relationship Between Body Weight and Stress and Nutritional Status in Turkish Women. Pakistan Journal of Nutrition. 6 (4). P.p. 339-344.

Sausenthaler. S. (2009). Stress-related maternal factors and childhood eczema. $J$ Investig Allergol Clin Immuonol. 19. P.p.481-487.

Schneider M, Roughton E, Koehler A, Lubach G. (1999). Growth and development following prenatal stress exposure in primates: an examination of ontogenetic vulnerability. Child Dev. 70. P.p. 263-74.

Schneider ML, Moore CF, Kraemer GW, Roberts AD, DeJesus OT. (2002). The impact of prenatal stress, fetal alcohol exposure, or both on development: perspectives from a primate model. Psychoneuroendocrinology. 27. P.p. 285-98.

Stratakis CA, Chrousos GP. (1995). Neuroendocrinology and pathophysiology of the stress system. Ann N Y Acad Sci. 771. P.p. 1-18.

Van Bussel, J.C., Spitz, B., Demyttenaere, K. (2006). Women's mental health before, during, and after pregnancy: a populationbased controlled cohort study. Birth. 33 . P.p. 297-302.

Varkukla M. et al. (2009). National Health and Medical Research Council (NHMRC), Postnatal Depression:Not Just the Baby Blues, Comparative Therapy. 35 (1). Retrivied from www.nhmrc. Health.gov.au on 2012.

Wadhwa PD, Culhane JF, Rauh V, et al. (2001). Stress, infection and preterm birth: a biobehavioural perspective. Paediatr Perinatal Epidemiol. 15. P.p. 17.

Wright. Rosalind J, Robyn T. Cohen and Sheldon Cohen. (2005). The impact of stress on the development and expression of atopy. Current Opinion in Allergy and Clinical Immunology. 5. P.p. 23-29. 